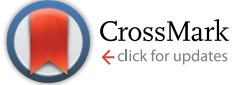

Cite this: RSC Adv., 2015, 5, 42407
Received 27th March 2015 Accepted 5th May 2015

DOI: 10.1039/c5ra05478h

www.rsc.org/advances

\title{
Iron-incorporated mesoporous silica for enhanced adsorption of tetracycline in aqueous solution $\dagger$
}

\author{
Ziyang Zhang, ${ }^{\text {ab }}$ Huachun Lan, ${ }^{a}$ Huijuan Liu, ${ }^{\text {a }}$ Haiyan $\mathrm{Li}^{\mathrm{c}}$ and Jiuhui $\mathrm{Qu}^{\mathrm{a}}$
}

Fe-incorporated SBA15 (Fe-SBA15) with different contents of Fe(III) was synthesized in order to enhance the adsorption of antibiotic tetracycline (TC) from aqueous solution. The influence of the Fe(III) content on the structural, textural and morphological properties of the adsorbents and the adsorption process of TC were investigated. The results showed that the adsorbents exhibited mesoporous structural order after co-condensation with different ratios of Fe/Si. As the Fe/Si ratio increased from 0.02 to 0.1 , the Fe(III) incorporated into the mesoporous silica framework offered abundant active sites for the adsorption of TC. The adsorption behavior was systematically studied and the results showed that Fe-SBA15 had higher adsorption capacity for TC than that of SBA15. The optimized solution $\mathrm{pH}$ for the adsorption was around 5.0 to 7.0, and the adsorption was endothermic and spontaneous. The adsorption mechanism mainly involved inner-sphere surface complexes formed between functional groups of TC and the Fe(III) on the adsorbent. The synthesized materials have excellent potential as adsorbents for environmental remediation.

\section{Introduction}

Tetracycline (TC), an important antibiotic, is heavily used as a medicine for treatment of infectious diseases and as a food additive in livestock and poultry breeding. ${ }^{1}$ TC can enter into the environment by the agricultural application of animal manure and sewage sludge, as well as from municipal effluents and soil waste..$^{2-4}$ Recently, the detection of TC in aquatic environments has raised concern about its potential to promote the development of antibiotic resistance genes and pose a risk to humans. ${ }^{5-8}$ As shown in Fig. S1, $\uparrow$ TC possesses tricarbonylamide, phenolic diketone, and dimethylamine groups, which cause complexity in its behavior in aquatic media. However, conventional water treatments are considered incomplete and inefficient for the removal of TC. ${ }^{9}$ Thus there is a demand of explore new effective treatment technologies for TC removal.

Recently, the adsorption technique has been received increasing attention due to its high efficiency and eco-friendliness. ${ }^{10}$ Several adsorbents, such as soils, ${ }^{9}$ carbon nanotubes, ${ }^{11}$ molybdenum disulfide, ${ }^{12} \mathrm{SiO}_{2},{ }^{13}$ graphene, ${ }^{14}$ cross-linked chitosan, ${ }^{\mathbf{1 5}}$ microscale zerovalent iron $^{\mathbf{1 6}}$ and mesoporous silica

${ }^{a}$ Key Laboratory of Drinking Water Science and Technology, Research Center for Eco-Environmental Sciences, Chinese Academy of Sciences, Beijing 100085, China. E-mail: hjliu@rcees.ac.cn

${ }^{b}$ University of Chinese Academy of Sciences, Beijing 100039, China

${ }^{c}$ Key Laboratory of Urban Stormwater System and Water Environment of Ministry of Education, Beijing University of Civil Engineering and Architecture, Beijing 100044, China

$\dagger$ Electronic supplementary information (ESI) available. See DOI: $10.1039 / \mathrm{c} 5 \mathrm{ra} 05478 \mathrm{~h}$ materials ${ }^{17}$ have been used to eliminate TC from aquatic solution. Among these adsorbents, mesoporous silica materials have high potential for application because of their high surface area, uniform pore size distribution (2-30 $\mathrm{nm}$ ) and large pore size. ${ }^{18,19}$ But pure mesoporous silica materials have little adsorption capacity toward TC. ${ }^{15,20}$ In a number of studies, iron species-rich materials such as amorphous ferric oxide, goethite, soils and ferrihydrite have been used as adsorbents due to their high reactivity. ${ }^{1521-24}$ The adsorption mechanism mainly involves the formation of inner-sphere complexes between the adsorbates and Fe(III) hydrated species. ${ }^{\mathbf{1 2 , 2 4}}$ However, most of these materials have relatively low surface area and the numbers of useful active sites are limited. Therefore, we propose to incorporate iron into a framework of mesoporous silica materials to overcome the difficulties mentioned above. The high surface area, large pore size and uniform mesoporous of silica materials could offer abundant active sites for iron incorporation and would be useful for the removal of pollutants from water.

The aim of this study was to synthesize Fe(III)-incorporated mesoporous silica materials to enhance the adsorption capacity of TC. The Fe(III)-incorporated mesoporous materials (Fe-SBA15) were prepared with different $\mathrm{Fe} / \mathrm{Si}$ ratios, the samples were systematically characterized and the influence of iron on the morphological properties was investigated. The influence of iron content on the adsorption properties was investigated by kinetic and isotherm measurements. Furthermore, the adsorption data obtained at different $\mathrm{pH}, \mathrm{NaCl}$ concentrations and temperatures were evaluated to gain insight into the adsorption process. FTIR 
and XPS were used to investigate the mechanism of the adsorption process.

\section{Experimental}

\section{Materials and chemicals}

The hydrochloride salt of tetracycline (TC) was obtained from Sigma Co. and used without further purification. Tetraethyl orthosilicate (TEOS, 98\%) and pluronic P123 $\left(\mathrm{PEO}_{20} \mathrm{PPO}_{70^{-}}\right.$ $\mathrm{PEO}_{20}, M_{\mathrm{av}}=5800$ ) were obtained from Alfa Aesar Corp. Acetonitrile and methanol were HPLC grade and obtained from Fisher Scientific Corp. Other chemicals including sodium hydroxide, hydrochloric acid, iron nitrate and oxalic acid were of analytical grade. All solutions were prepared in high-purity water (Milli-Q).

\section{Adsorbent preparation}

Fe(III)-incorporated SBA15 was prepared by using TEOS as the silica source and pluronic P123 as the templating reagent. ${ }^{18}$ In brief, $2 \mathrm{~g}$ of P123 was dissolved in $70 \mathrm{~mL}$ of $2 \mathrm{M} \mathrm{HCl}$ solution at $40{ }^{\circ} \mathrm{C}$. TEOS $(4.5 \mathrm{~mL})$ and the desired amount of iron nitrate $(\mathrm{Fe} / \mathrm{Si}$ molar ratio $=0,0.02,0.05,0.1,0.2)$ was added drop-wise to the solution. The solution was stirred vigorously for $20 \mathrm{~h}$ at $40{ }^{\circ} \mathrm{C}$. It was then transferred into an autoclave and aged for $24 \mathrm{~h}$ at $100{ }^{\circ} \mathrm{C}$. The resultant solid was filtered, washed, and dried at $60^{\circ} \mathrm{C}$ for $15 \mathrm{~h}$. In order to remove the organic template, the samples were calcined at $550{ }^{\circ} \mathrm{C}$ for $8 \mathrm{~h}$ at a heating rate of $1 \mathrm{~K} \mathrm{~min}^{-1}$, and the Fe-SBA-15 mesoporous materials were finally obtained. Samples with different Fe/Si molar ratios of 0, 0.02, 0.05, 0.1, 0.2 were named SBA15, Fe-SBA15-0.02, Fe-SBA15-0.05, Fe-SBA15-0.1, Fe-SBA15-0.2, respectively.

\section{Characterization}

X-ray powder diffraction (XRD) patterns were obtained using an $X^{\prime}$ pert PRO MPD (PANalytical, Holland). The nitrogen adsorption-desorption isotherms were recorded by a Micromeritics ASAP 2020 HD88 (Mike, USA) to determine the surface area, pore size distribution (PSD) and pore volume of all samples. The surface of the samples and iron oxide particles size were examined by transmission electron microscopy (TEM, JEM2100F, Japan) coupled to an EDX analyzer for Fe detection over the sample surface. A Tenson 27 FTIR Spectrometer (Bruker, Germany) and XPS (Kratos AXIS ULTRA, UK) were used to determine the vibration frequency changes and chemical analysis of virgin and TC loaded Fe-SBA15.

\section{TC adsorption experiments}

All batch experiments were conducted in the dark to inhibit the potential photo-degradation of TC. To elucidate the function of iron in the process of TC adsorption, Fe-SBA15 with different $\mathrm{Fe} / \mathrm{Si}$ ratios were used to investigate the adsorption properties using kinetic and isotherm measurements. The kinetic adsorption studies were investigated by adding $0.25 \mathrm{~g}$ adsorbents with different $\mathrm{Fe} / \mathrm{Si}$ ratios into $500 \mathrm{~mL}$ solutions containing TC with the initial concentration of $0.1 \mathrm{mM}$. Samples were collected at appropriate time intervals and filtered through a $0.45 \mu \mathrm{m}$ membrane filter, and analyzed for TC concentration.

Adsorption isotherm experiments were carried out by adding $0.025 \mathrm{~g}$ of the adsorbents to $50 \mathrm{~mL}$ solutions containing $\mathrm{TC}$ at $0.01,0.03,0.05,0.07,0.1,0.15$ and $0.2 \mathrm{mM}$. The solution $\mathrm{pH}$ was maintained at $5.0 \pm 0.1$ by using hydrochloric acid and sodium hydroxide. The mixed solutions were shaken at a speed of 150 rpm for $24 \mathrm{~h}$ at $298 \mathrm{~K}$ to reach equilibrium. The adsorption isotherm data were fitted with Langmuir and Freundlich models as presented in eqn (1) and (2), respectively. The separation factor $\left(R_{\mathrm{L}}\right)$ was used to determine the feasibility of adsorption in a given concentration range, as shown by eqn (3). ${ }^{16}$

$$
\begin{gathered}
Q_{\mathrm{e}}=\frac{Q_{\mathrm{max}} b C_{\mathrm{e}}}{1+b C_{\mathrm{e}}} \\
Q_{\mathrm{e}}=K_{\mathrm{f}} C_{\mathrm{e}}{ }^{1 / n} \\
R_{\mathrm{L}}=\frac{1}{1+b C_{0}}
\end{gathered}
$$

where $C_{0}$ and $C_{\mathrm{e}}$ are the initial and equilibrium concentration of TC (mmol L $\left.{ }^{-1}\right)$, respectively; $Q_{\max }$ is the maximum adsorption capacity $\left(\mathrm{mmol} \mathrm{kg} \mathrm{kg}^{-1}\right), b$ is a measure of the energy of adsorption; $K_{\mathrm{f}}$ is the Freundlich adsorption constant and $n$ is related to the adsorption intensity.

To further study the adsorption of TC on Fe-SBA15, Fe-SBA150.05 was used in the experiments on $\mathrm{pH}$ effect, ionic strength and adsorption thermodynamic. The experiments were conducted by adding a mass of $0.025 \mathrm{~g}$ Fe-SBA15-0.05 or SBA15 into $50 \mathrm{~mL}$ solutions containing TC at the initial concentration of $0.1 \mathrm{mM}$ with different ionic strengths $(1,10,50 \mathrm{mM} \mathrm{NaCl})$. The solution $\mathrm{pH}$ was adjusted to different values between 3 to 9 using hydrochloric acid and sodium hydroxide. Other experimental conditions were the same as mentioned in adsorption isotherms.

Adsorption thermodynamics were investigated at 298, 308 and $318 \mathrm{~K}$. The changes in the thermodynamic parameters of the adsorption process are expressed by eqn (4) and (5). ${ }^{14}$

$$
\begin{aligned}
& \ln K_{\mathrm{d}}=\frac{-\Delta H^{\mathrm{o}}}{R T}+\frac{\Delta S^{\mathrm{o}}}{R} \\
& \Delta G^{\mathrm{o}}=\Delta H^{\mathrm{o}}-T \Delta S^{\mathrm{o}}
\end{aligned}
$$

where $K_{\mathrm{d}}$ is the distribution coefficient, $\Delta H^{\mathrm{o}}$ is the change of enthalpy ( $\left.\mathrm{kJ} \mathrm{mol}^{-1}\right), \Delta S^{\mathrm{o}}$ is the change of entropy $\left(\mathrm{J} \mathrm{mol}^{-1} \mathrm{~K}^{-1}\right.$ ), $\Delta G^{\mathrm{o}}$ is the change of Gibbs free energy $\left(\mathrm{kJ} \mathrm{mol}^{-1}\right), T$ is the absolute temperature in Kelvin (K), and $R$ is the gas constant (8.314 $\left.\mathrm{J} \mathrm{mol}^{-1} \mathrm{~K}^{-1}\right)$.

The TC concentrations were determined by HPLC (Agilent 1260 , USA) at a wavelength of $360 \mathrm{~nm}$. The mobile phase consisting of $10 \mathrm{mM}$ aqueous oxalic acid-acetonitrile-methanol $(67: 22: 11, \mathrm{v} / \mathrm{v})$ at a flow rate of $1 \mathrm{~mL} \mathrm{~min}^{-1}$.

\section{Results and discussion}

\section{Structural, textural, and morphological properties of Fe-SBA15}

The $\mathrm{N}_{2}$ adsorption-desorption isotherms, corresponding $\mathrm{BJH}$ pore size distribution, small-angle and wide-angle X-ray 
diffraction patterns of Fe-SBA15 with different $\mathrm{Fe} / \mathrm{Si}$ ratios are shown in Fig. 1. The results show that the $\mathrm{N}_{2}$ adsorptiondesorption isotherms of the adsorbents exhibited classical type IV isotherms with H1-type hysteresis, which indicated that the adsorbents present a well-defined pore structure..$^{25}$ The results were also confirmed by the narrow pore size distribution shown in Fig. 1(b). Compared with SBA15, the Fe(III) co-condensed samples exhibited a higher surface area, pore volume and pore size (Table 1). These results were also clearly evident in the $\mathrm{N}_{2}$ adsorption-desorption isotherms, with a shift in the hysteresis loop to higher $P / P_{0}$. Fig. $1(\mathrm{c})$ shows the small-angle $\mathrm{X}$ ray diffraction patterns for all samples. The results show that the SBA15 displayed well-resolved XRD lines, confirming the hexagonal ordering of the samples. ${ }^{26}$ The content of Fe(III)incorporation in SBA-15 has a direct impact on the characteristic $p 6 \mathrm{~mm}$ hexagonal symmetry. As the content of $\mathrm{Fe}(\mathrm{III})$-incorporation increased, the samples displayed more poorly defined XRD lines; the (110) and (200) reflections of the Fe-SBA15 samples were rather broad or disappeared, indicating the deformation of the hexagonal structure. ${ }^{25}$ Furthermore, the shift of the (100) reflection to lower $2 \theta$ indicated the expansion in the unit cell dimension caused by the incorporation of largersized Fe(III) into the framework. Fig. 1(d) shows the wide-angle $\mathrm{X}$-ray diffraction patterns of all Fe-SBA15. The broad peak at $2 \theta \sim 23^{\circ}$ shows amorphous character of silica, and the gradual decreasing in intensity indicates the less extend of structure formed by the increasing amount of $\mathrm{Fe}$ (III) incorporated into the framework of samples. For $\mathrm{Fe} / \mathrm{Si}=0.02,0.05$ and 0.1 , no significant peaks are observed at $2 \theta \sim 30-40^{\circ}$ where are attributed to the $\mathrm{Fe}_{2} \mathrm{O}_{3}$, suggested that no impurity crystalline iron oxides formed. But the sample with $\mathrm{Fe} / \mathrm{Si}=0.2$ displays new weak peak at $2 \theta \sim 35.5^{\circ}$ indicates crystalline iron oxides may be formed.

Representative TEM images and EDX analyses of Fe-SBA15 with different $\mathrm{Fe} / \mathrm{Si}$ ratios are depicted in Fig. 2. From the TEM images we can see that the silica pore structure remains
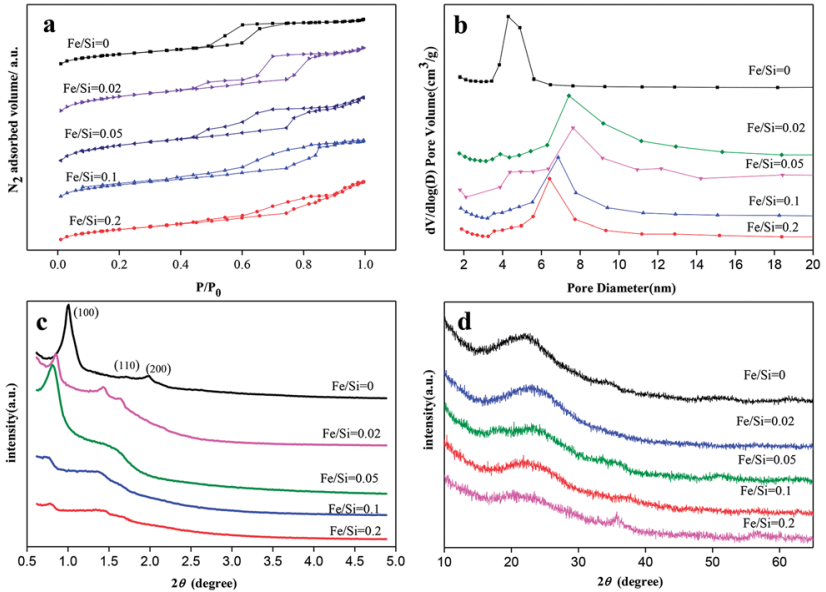

Fig. 1 Characterization of Fe-SBA15 with different Fe/Si ratios. (a) $\mathrm{N}_{2}$ adsorption-desorption isotherms, (b) corresponding $\mathrm{BJH}$ pore size distribution, (c) small-angle X-ray diffraction patterns and (d) wideangle $\mathrm{X}$-ray diffraction patterns.
Table 1 Pore structural properties of samples

\begin{tabular}{llll}
\hline & $\mathrm{BET}\left(\mathrm{m}^{2} \mathrm{~g}^{-1}\right)$ & $\begin{array}{l}\text { Pore volume } \\
\left(\mathrm{cm}^{3} \mathrm{~g}^{-1}\right)\end{array}$ & $\begin{array}{l}\text { Pore size } \\
(\mathrm{nm})\end{array}$ \\
\hline $\mathrm{Fe} / \mathrm{Si}=0$ & 596.62 & 0.67 & 4.49 \\
$\mathrm{Fe} / \mathrm{Si}=0.02$ & 635.63 & 1.27 & 8.05 \\
$\mathrm{Fe} / \mathrm{Si}=0.05$ & 638.12 & 1.45 & 9.11 \\
$\mathrm{Fe} / \mathrm{Si}=0.1$ & 637.18 & 1.08 & 6.23 \\
$\mathrm{Fe} / \mathrm{Si}=0.2$ & 615.75 & 1.00 & 6.13
\end{tabular}
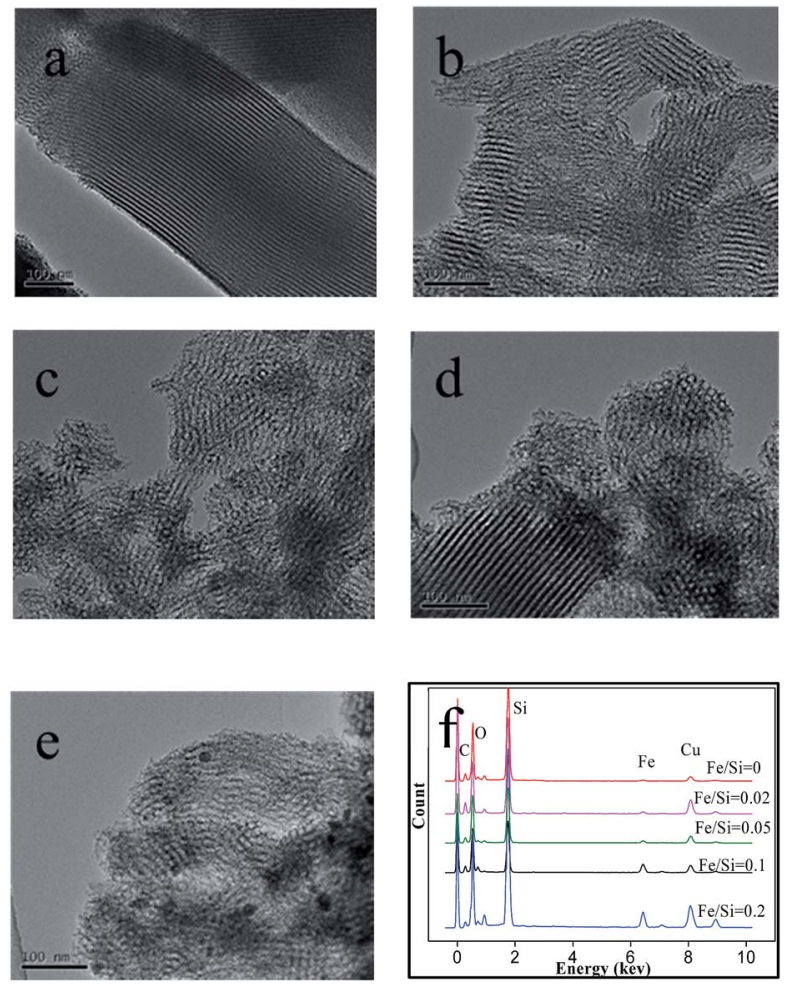

Fig. 2 Representative TEM images and EDX analyses of Fe-SBA15. (a) $\mathrm{Fe} / \mathrm{Si}=0$, (b) $\mathrm{Fe} / \mathrm{Si}=0.05$, (c) $\mathrm{Fe} / \mathrm{Si}=0.02$, (d) $\mathrm{Fe} / \mathrm{Si}=0.1$, (e) $\mathrm{Fe} / \mathrm{Si}=$ 0.2 , (f) EDX analyses.

unaltered after the corporation of Fe(III). For the Fe-SBA15 with $\mathrm{Fe} / \mathrm{Si}$ ratios of $0.02,0.05$ and 0.1 , most $\mathrm{Fe}(\mathrm{III})$ is incorporated into the mesoporous silica framework, since no iron oxide particles were found within or outside of the framework of the silica matrix. Furthermore, spot EDX analyses also gave evidence of the presence of Fe within the SBA15 structure. As the Fe/Si ratio increased to 0.2, TEM image shows iron oxide particles formed with different sizes, including particles located within the mesoporous silica matrix and particle aggregates on the outer surface of the silica. These results accord with the results of the $\mathrm{X}$-ray diffraction.

\section{The effect of iron content on the adsorption of TC: kinetic and isotherm measurements}

The adsorption kinetics of Fe-SBA15 with different Fe/Si ratios are shown in Fig. 3. Compared with the SBA15, all Fe-SBA15 had 


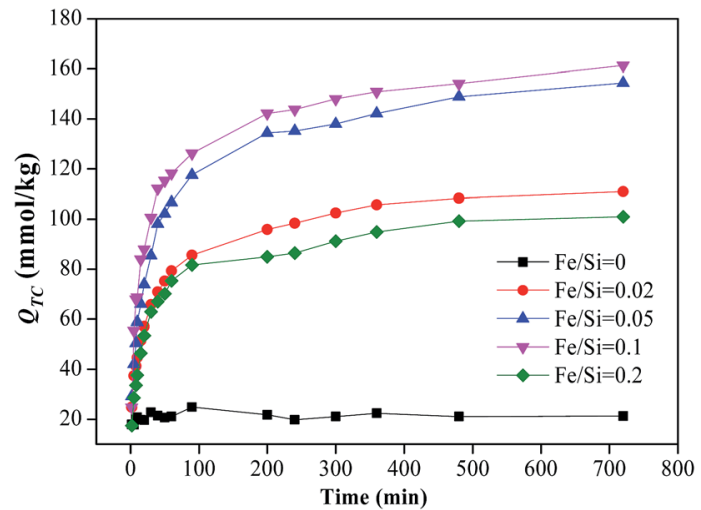

Fig. 3 Adsorption kinetics of TC on Fe-SBA15. Experimental conditions: $[\mathrm{TC}]_{0}=0.1 \mathrm{mmol} \mathrm{L}^{-1}, m=0.5 \mathrm{~g} \mathrm{~L}^{-1}, T=298 \mathrm{~K},[\mathrm{NaCl}]=10$ mmol L ${ }^{-1}$.

higher adsorption capacity for TC. Furthermore, the content of $\mathrm{Fe}(\mathrm{III})$ influenced the adsorption of TC remarkably, such that the adsorption capacity of TC increased as the Fe/Si ratios increased from 0.02 to 0.1 , but decreased when the $\mathrm{Fe} / \mathrm{Si}$ ratio increased to 0.2. The pseudo-first-order and pseudo-second-order models were used to interpret the experimental data. ${ }^{12,27}$ The values of kinetic parameters and correlation coefficients are shown in Table 2. The pseudo-second-order model fitted the adsorption process better than the pseudo-first-order model, which suggested that the adsorption may be chemisorption, and that the adsorption probably occurred by surface complexation reactions between TC and the sorption sites on the adsorbent.

The adsorption isotherms of TC onto Fe-SBA15 with different $\mathrm{Fe} / \mathrm{Si}$ ratios are shown in Fig. 4. The incorporation of $\mathrm{Fe}$ (III) increased the adsorption ability of TC greatly, and the adsorption of TC increased with increased $\mathrm{Fe}(\mathrm{III})$ content and reached a maximum when the $\mathrm{Fe} / \mathrm{Si}$ ratio was 0.1 . To investigate the adsorption isotherms further, the Langmuir and Freundlich models were used to represent the behavior of adsorption. The parameters and coefficients of the two models are shown in Table 3. Compared with the Freundlich model, the Langmuir model fitted the adsorption better $\left(R^{2}=0.96-0.99\right)$, which suggested that the adsorption of TC on Fe-SBA15 was probably monolayer molecular adsorption. ${ }^{\mathbf{1 1} 14}$ The $R_{\mathrm{L}}$ values for all the adsorbents were in the range 0.008-0.6 (shown in Fig. S2†),

Table 2 Kinetic parameters and correlation coefficients for the adsorption of TC onto Fe-SBA15

\begin{tabular}{|c|c|c|c|c|c|c|}
\hline & \multicolumn{3}{|c|}{ Pseudo-first-order } & \multicolumn{3}{|c|}{ Pseudo-second-order } \\
\hline & $\begin{array}{l}Q_{\mathrm{e}} \\
\left(\mathrm{mmol} \mathrm{kg}^{-1}\right)\end{array}$ & $K_{1}$ & $R^{2}$ & $\begin{array}{l}Q_{\mathrm{e}} \\
\left(\mathrm{mmol} \mathrm{kg}{ }^{-1}\right)\end{array}$ & $K_{2}$ & $R^{2}$ \\
\hline $\mathrm{Fe} / \mathrm{Si}=0$ & 9.43 & 0.019 & 0.96 & 29.85 & 0.0023 & 0.98 \\
\hline $\mathrm{Fe} / \mathrm{Si}=0.02$ & 65.50 & 0.0070 & 0.95 & 112.35 & 0.00043 & 0.99 \\
\hline $\mathrm{Fe} / \mathrm{Si}=0.05$ & 85.60 & 0.0059 & 0.88 & 161.55 & 0.00034 & 0.99 \\
\hline $\mathrm{Fe} / \mathrm{Si}=0.1$ & 93.06 & 0.0060 & 0.93 & 155.52 & 0.00027 & 0.99 \\
\hline $\mathrm{Fe} / \mathrm{Si}=0.2$ & 56.30 & 0.0062 & 0.91 & 100.35 & 0.00033 & 0.99 \\
\hline
\end{tabular}

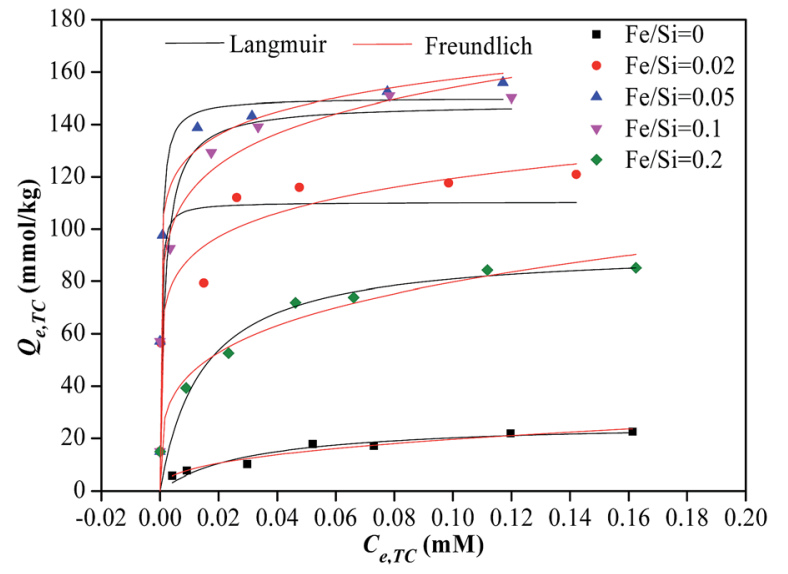

Fig. 4 Adsorption isotherms of TC onto Fe-SBA15. Experimental conditions: $[\mathrm{TC}]_{0}=0.01-0.2 \mathrm{mmol} \mathrm{L}^{-1}, m=0.5 \mathrm{~g} \mathrm{~L}^{-1}, T=298 \mathrm{~K}$, $[\mathrm{NaCl}]=10 \mathrm{mmol} \mathrm{L}^{-1}$.

indicating that the adsorption of TC on Fe-SBA15 was favorable in the concentration range studied. ${ }^{\mathbf{1 4}}$ Comparing samples with different $\mathrm{Fe} / \mathrm{Si}$ ratios, the $Q_{\max }$ followed the order Fe-SBA15-0.1 > Fe-SBA15-0.05 $>$ Fe-SBA15-0.02 > Fe-SBA15-0.2 > SBA15. Furthermore, $1 / n$ is a constant indicative of adsorption intensity or surface heterogeneity; the values of $1 / n$ were less than 1.0 for all samples, indicating that the adsorption of TC onto Fe-SBA15 was favorable. ${ }^{14}$

As discussed in the description of kinetic and isotherm results, the presence of $\mathrm{Fe}(\mathrm{III})$ influenced the adsorption behavior significantly. The Fe(III) enhanced the adsorption of TC greatly: the $Q_{\max }$ increased when the $\mathrm{Fe} / \mathrm{Si}$ ratios increased from 0.02 to 0.05 , and was nearly constant for $\mathrm{Fe} / \mathrm{Si}=0.1$, but when the content of $\mathrm{Fe}(\mathrm{III})$ increased further, the $Q_{\max }$ decreased. The phenomena can be attributed to the differences in structure and morphological properties of the adsorbents. As shown in Fig. 1 and Table 1, the addition of Fe(III) could increase the BET surface area, pore volume and pore size, which is favorable for the adsorption of TC onto the adsorbents. Furthermore, compared with SBA15, the incorporation of iron into the framework of the adsorbents could offer abundant sorption sites, and enhanced the adsorption capacity of TC. ${ }^{\mathbf{1 5 , 2 1 , 2 8}}$ However, the adsorption capacity of TC decreased when the $\mathrm{Fe} / \mathrm{Si}$ ratio increased to 0.2 . The high content of iron would

Table 3 Isotherm parameters and coefficients of adsorption TC on Fe-SBA15

\begin{tabular}{|c|c|c|c|c|c|c|}
\hline & \multicolumn{3}{|l|}{ Langmuir } & \multicolumn{3}{|c|}{ Freundlich } \\
\hline & $\begin{array}{l}Q_{\max } \\
\left(\mathrm{mmol} \mathrm{kg}{ }^{-1}\right)\end{array}$ & $b$ & $R^{2}$ & $n$ & $K_{\mathrm{f}}$ & $R^{2}$ \\
\hline $\mathrm{Fe} / \mathrm{Si}=0$ & 21.11 & 32.39 & 0.96 & 1.63 & 48.82 & 0.93 \\
\hline $\mathrm{Fe} / \mathrm{Si}=0.02$ & 108.69 & 766.66 & 0.99 & 8.62 & 160.77 & 0.87 \\
\hline $\mathrm{Fe} / \mathrm{Si}=0.05$ & 151.97 & 672.80 & 0.99 & 7.29 & 209.01 & 0.99 \\
\hline $\mathrm{Fe} / \mathrm{Si}=0.1$ & 155.76 & 1103.09 & 0.99 & 10.44 & 193.46 & 0.97 \\
\hline $\mathrm{Fe} / \mathrm{Si}=0.2$ & 71.32 & 68.79 & 0.96 & 4.48 & 143.62 & 0.86 \\
\hline
\end{tabular}


decrease the pore volume and pore size, which would inhibit the adsorption of TC into the mesoporous structure of adsorbent. The decrease of pore volume and size was attributed to the blocking of mesopores or the aggregation of iron oxide particles.

The high adsorption capacity of TC onto Fe-SBA15 was caused by the high surface area, uniform mesoporous and abundance of sorption sites. The $Q_{\max }$ of TC calculated by the Langmuir isotherm was $155.76 \mathrm{mmol} \mathrm{kg}^{-1}$ for the $\mathrm{Fe} / \mathrm{Si}=0.1$. The adsorption capacity of TC on some other adsorbents such as apatite, ${ }^{27}$ cross-linked chitosan, ${ }^{11}$ microscale zerovalent iron, ${ }^{12}$ and magnetic porous carbon ${ }^{29}$ were $76.4 \mathrm{mmol} \mathrm{kg}^{-1}, 43.1$ mmol kg ${ }^{-1}, 48.7 \mathrm{mmol} \mathrm{kg}^{-1}$, and $53.0 \mathrm{mmol} \mathrm{kg}^{-1}$, respectively (Table 4). The adsorption capacity of Fe-SBA15 was relatively higher than these adsorbents which showed that the Fe-SBA15 exhibited good potential for the removal of TC from aqueous solution.

\section{Effect of $\mathrm{pH}$ and ionic strength on the adsorption of TC}

The effect of $\mathrm{pH}$ and ionic strength of adsorption of TC onto FeSBA15-0.05 and SBA15 are shown in Fig. 5. The results show that the incorporation of $\mathrm{Fe}(\mathrm{III})$ increased the adsorption capacity greatly for all $\mathrm{pH}$ values. Furthermore, different from SBA15, solution $\mathrm{pH}$ influenced the adsorption of TC greatly. The $\mathrm{pH}$ effect of Fe-SBA15 could be divided into three regions. The adsorption increased with increasing $\mathrm{pH}$ when $\mathrm{pH}<5.0$, and stayed nearly unchanged when $5<\mathrm{pH}<7$; when $\mathrm{pH}$ increased further, the adsorption decreased dramatically. These results were attributed to the speciation of TC in aqueous solution and the surface chemistry of the adsorbent. As shown in Fig. S3, $\dagger$ the zeta potential of Fe-SBA15 was mainly negative at all $\mathrm{pH}$ values. TC existed as cationic $\left(\mathrm{H}_{3} \mathrm{TC}^{+}\right)$, zwitterionic $\left(\mathrm{H}_{2} \mathrm{TC}^{ \pm}\right)$and anionic $\left(\mathrm{HTC}^{-}\right)$species under acidic and moderately acidic to neutral and alkaline condition. The adsorption edge of TC onto the adsorbent suggested that there were at least two surface complexation reactions involved as $\mathrm{pH}$ varied. ${ }^{21,22}$ The tricarbonylamide group and phenolic diketone group of TC could interact with the adsorbent surface in different $\mathrm{pH}$ ranges. In acidic to neutral conditions, $\mathrm{H}_{3} \mathrm{TC}^{+}$and $\mathrm{H}_{2} \mathrm{TC}^{ \pm}$caused by deprotonation of the tricarbonylamide group could interact with the surface sites of the adsorbent to form an inner-sphere complex. As the $\mathrm{pH}$ increased further, the phenolic diketone group of TC started to deprotonate, and served as the group involved in complexation with the adsorbent surface. The

Table 4 Adsorption capacities of TC on different adsorbents based on Langmuir model

\begin{tabular}{lllll}
\hline & & \multicolumn{3}{c}{$Q_{\mathrm{e}}$} \\
Adsorbent & $\mathrm{pH}$ & $T(\mathrm{~K})$ & $\left(\mathrm{mmol} \mathrm{kg}^{-1}\right)$ & Reference \\
\hline Apatite & Neutral & 295 & 76.4 & 27 \\
Cross-linked chitosan & 3.2 & 298 & 43.1 & 11 \\
Microscale zerovalent iron & 3.0 & 303 & 48.7 & 12 \\
Magnetic porous carbon & 3.1 & 303 & 53.0 & 29 \\
Fe-SBA15 & 5.0 & 298 & 155.76 & This study
\end{tabular}

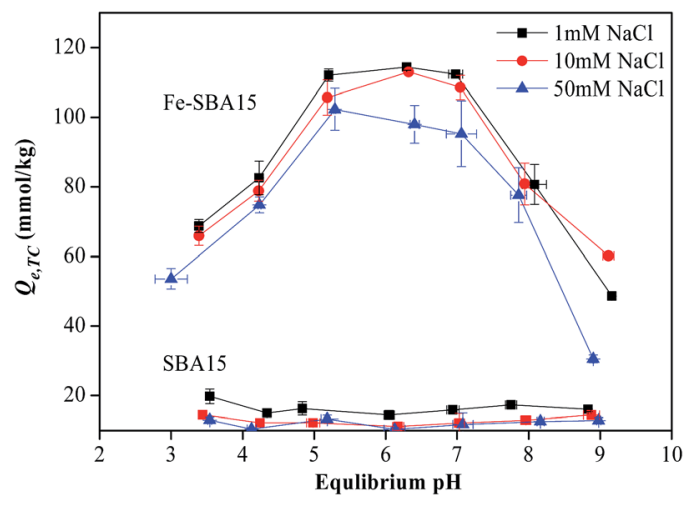

Fig. 5 Influence of solution $\mathrm{pH}$ and ionic strength on the adsorption. Experimental conditions: $[\mathrm{TC}]_{0}=0.1 \mathrm{mmol} \mathrm{L}^{-1}, m=0.5 \mathrm{~g} \mathrm{~L}^{-1}, T=298 \mathrm{~K}$.

results were consistent with the adsorption of TC on goethite and hematite. ${ }^{\mathbf{2 1 , 2 2}}$ The adsorption decreased at $\mathrm{pH}>7$, which reflected the unfavorable electrostatic conditions for TC molecules and Fe-SBA15 surfaces. For SBA15, electrostatic interactions may play an important role in the adsorption, thus the adsorption of TC decreased slightly as the $\mathrm{pH}$ increased.

The adsorption of TC on Fe-SBA15 showed a slight decrease with increasing ionic strength from $1 \mathrm{mM}$ to $50 \mathrm{mM}$ at all $\mathrm{pH}$ values. Inner- and outer-sphere surface complexes can be distinguished by investigating the effects of ionic strength. ${ }^{22}$ Outer-sphere complexes are greatly influenced by increasing ionic strength, while inner-sphere complexes are hardly influenced. Hence, the adsorption process of TC on Fe-SBA15 suggested that the adsorption was mainly caused by inner-sphere surface complexes. Furthermore, after TC adsorption, the zeta potential of the adsorbent shifted towards more negative values at all $\mathrm{pH}$ values (shown in Fig. S3†), which suggested that surface complexation may be involved in the adsorption of TC onto Fe-SBA15. ${ }^{30}$

\section{Effect of temperature on the adsorption of TC}

The influence of temperature on TC adsorption onto Fe-SBA15 was investigated, and the results are shown in Fig. 6(a). The adsorption capacity was enhanced with increasing temperature from $298 \mathrm{~K}$ to $318 \mathrm{~K}$, suggesting that the process was endothermic and that the adsorption was more favorable at higher temperature. To further investigate the adsorption process, the thermodynamic parameters were calculated and listed in Table 5. Estimates of $\Delta H^{\mathrm{o}}$ and $\Delta S^{\mathrm{o}}$ could be obtained from the slope and intercept of Van't Hoff plot ln $K_{\mathrm{d}} v s .1 / T$ as shown in Fig. 6(b). The positive $\Delta H^{\mathrm{o}}$ value indicated that the interaction between TC and adsorbent was an endothermic process. Furthermore, the value of $\Delta H^{\mathrm{o}}$ was in the range of (30-70) $\mathrm{kJ} \mathrm{mol}^{-1}$, indicating that the adsorption mechanism of TC on FeSBA15 was mainly chemisorption. ${ }^{15} \Delta S^{\mathrm{o}}$ was $156.72 \mathrm{~J} \mathrm{~mol}^{-1} \mathrm{~K}^{-1}$, indicating that the randomness increased at the solid-liquid interface during TC adsorption. The negative values of $\Delta G^{\mathrm{o}}$ for all three temperatures implied that the adsorption process was spontaneous. 

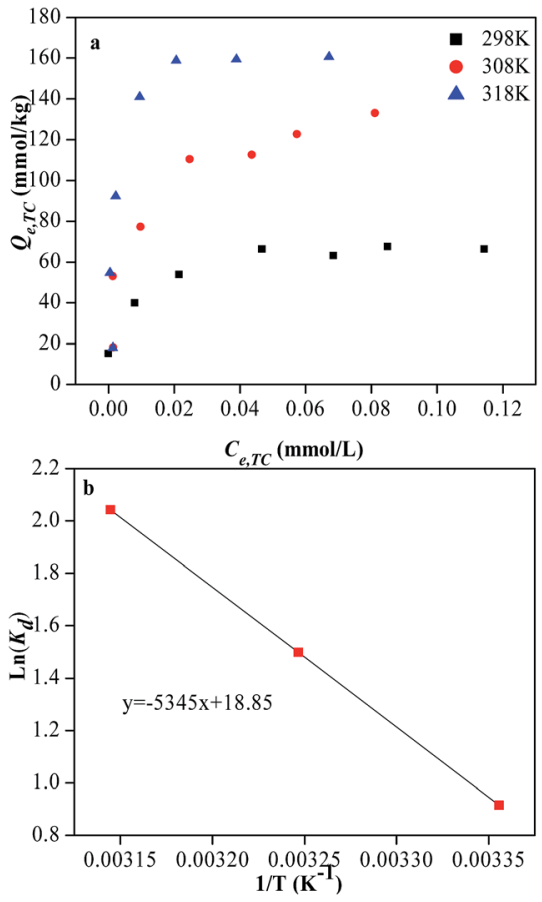

Fig. 6 Effect of temperature (a) and Van't Hoff plot (b) for TC adsorption on Fe-SBA15.

Table 5 Thermodynamic parameters of TC adsorption onto Fe-SBA15

\begin{tabular}{lllll}
\hline $\begin{array}{l}\text { Temperature } \\
(\mathrm{K})\end{array}$ & $K_{\mathrm{d}}$ & $\begin{array}{l}\Delta G^{\mathrm{o}} \\
\left.(\mathrm{kJ} \mathrm{mol})^{-1}\right)\end{array}$ & $\begin{array}{l}\Delta H^{\mathrm{o}} \\
\left(\mathrm{kJ} \mathrm{mol}^{-1}\right)\end{array}$ & $\begin{array}{l}\Delta S^{\mathrm{o}} \\
\left(\mathrm{J} \mathrm{mol}^{-1} \mathrm{~K}^{-1}\right)\end{array}$ \\
\hline 298 & 2.49 & -2.26 & 44.43 & 156.72 \\
308 & 4.47 & -3.83 & & \\
318 & 7.71 & -5.40 & & \\
& & & &
\end{tabular}

\section{FTIR and XPS analysis}

To further investigate the adsorption of TC onto Fe-SBA15, the FTIR and XPS spectra of the adsorbent before and after adsorption were examined. As shown in Fig. 7, the FTIR spectra of Fe-SBA15 showed several peaks, such as those at $800 \mathrm{~cm}^{-1}$, $1085 \mathrm{~cm}^{-1}, 1627 \mathrm{~cm}^{-1}$ and $3425 \mathrm{~cm}^{-1}$, that could be attributed to the symmetric and antisymmetric stretching vibrations of tetrahedral $\mathrm{SiO}_{4}$ units, $\mathrm{H}_{2} \mathrm{O}$ adsorbed in mesoporous silica, and stretching vibrations of terminal $\mathrm{Si}-\mathrm{OH}$ groups with significant hydrogen-bonding interaction. ${ }^{28,31,32}$ After TC adsorption, most of the peaks of the adsorbent were unchanged, suggesting that the adsorption process did not alter the structure of the adsorbent. Several new peaks appear at $1485 \mathrm{~cm}^{-1}, 2929 \mathrm{~cm}^{-1}$ and $2858 \mathrm{~cm}^{-1}$ that were attributed to the vibration of the $\mathrm{C}=\mathrm{C}$ skeleton, and $\mathrm{C}-\mathrm{H}$ stretching of $\mathrm{CH}_{2}$ and $\mathrm{CH}_{3}$ caused by the aromatic groups of TC. ${ }^{1,31}$ The FTIR spectrum showed that TC was adsorbed onto the adsorbent and that the structures of the samples were stable after adsorption.

Fig. 8 shows the high-resolution Fe 2p, Si 2p and O 1s spectra of the adsorbent before and after adsorption. For the Fe 2p XPS

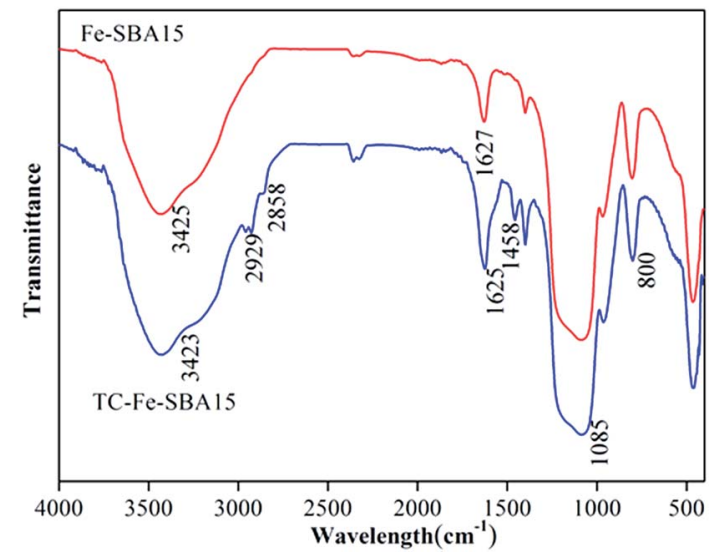

Fig. 7 FTIR spectra of the adsorbents before and after adsorption of TC.

spectra, the adsorbent has two well-defined peaks assigned to Fe $2 p_{3 / 2}(711.4 \mathrm{eV})$ and $\mathrm{Fe} 2 \mathrm{p}_{1 / 2}(724.6 \mathrm{eV})$, which suggested the presence of $\mathrm{Fe}(\mathrm{III})$ on the adsorbent. ${ }^{19,28}$ After the TC adsorption, both the Fe $2 p_{3 / 2}$ and $\mathrm{Fe} 2 \mathrm{p}_{1 / 2}$ showed a slight positive shift in binding energy, which may be caused by the complexation between the adsorbent and adsorbate. The Si 2p peak showed only a single peak at about $103.1 \mathrm{eV} \cdot{ }^{\mathbf{2 8 , 3 1}}$ After TC adsorption, the peak shifted to more positive binding energy. As the Fe(III) in the framework could decrease the binding energy of Si $2 \mathrm{p},{ }^{31}$ the complexation between $\mathrm{Fe}(\mathrm{III})$ in the framework and TC induced a slight positive shift in the bonding energy of Si 2 p. For O $1 \mathrm{~s}$ spectra, the adsorbent showed two peaks at $532.4 \mathrm{eV}$ and 529.5 $\mathrm{eV}$, which could due to the binding energy of $\mathrm{Si}-\mathrm{O}$ and $\mathrm{Fe}-\mathrm{O}$. After TC adsorption, the peak of Fe-O nearly disappeared and the $\mathrm{Si}-\mathrm{O}$ peak shifted to a higher binding energy, suggesting that an interaction took place between TC and Fe(III).

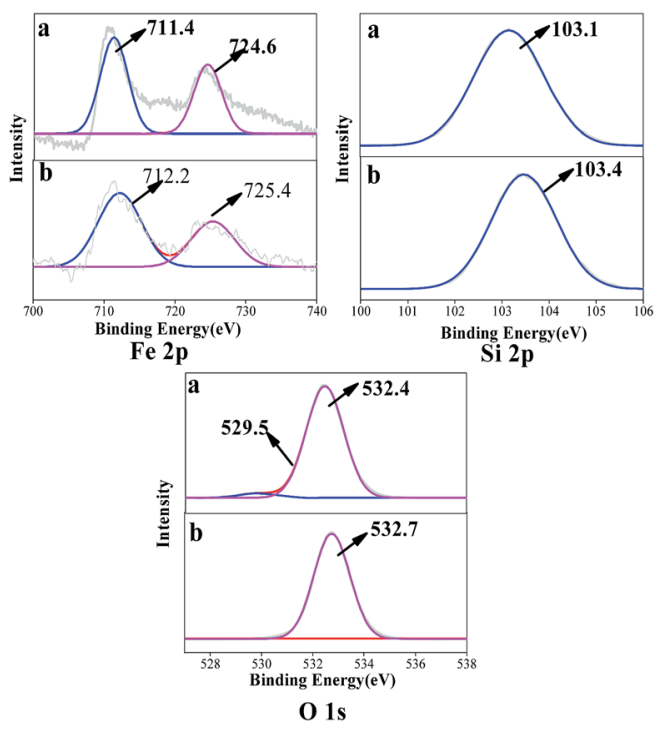

Fig. 8 XPS spectra of Fe $2 p$, Si $2 p$ and $O$ 1s for the adsorbents before and after adsorption. (a) adsorbent; (b) TC-loaded adsorbent. 


\section{Conclusions}

A series of adsorbents with different amounts of Fe(III) incorporated into SBA15 were prepared. The adsorbents showed a well-defined pore structure after the incorporation of $\mathrm{Fe}(\mathrm{III})$. As the $\mathrm{Fe} / \mathrm{Si}$ ratio increased from 0.02 to 0.1 , most of $\mathrm{Fe}(\mathrm{III})$ was mainly incorporated into the framework of the mesoporous silica. Due to abundance of sorption sites caused by the incorporation of Fe(III), Fe-SBA15 had higher adsorption capacity for TC than SBA15, and the isotherms were fitted by the Langmuir model. The adsorption capacity increased with increasing $\mathrm{Fe} / \mathrm{Si}$ ratio, and the maximum was achieved at $\mathrm{Fe} / \mathrm{Si}=0.1$. The adsorption capacity declined with further increases in the $\mathrm{Fe} / \mathrm{Si}$ ratio, which was mainly caused by the blocking of the mesoporous or the aggregation of iron oxide particles. Solution $\mathrm{pH}$ affected the adsorption significantly and the optimized $\mathrm{pH}$ was around 5.0 to 7.0. The adsorption was mainly caused by innersphere surface complexes formed between functional groups of TC and the $\mathrm{Fe}(\mathrm{III})$ on the adsorbent.

\section{Acknowledgements}

This work was supported by the National Science Fund for Distinguished Young Scholars of China (Grant no. 51225805) and the National High Technology Research and Development program (Grants 2012AA062606) of China.

\section{Notes and references}

1 C. Gu and K. G. Karthikeyan, Environ. Sci. Technol., 2005, 39, 2660-2667.

2 J. R. V. Pils and D. A. Laird, Environ. Sci. Technol., 2007, 41, 1928-1933.

3 A. K. Sarmah, M. T. Meyer and A. B. A. Boxall, Chemosphere, 2006, 65, 725-759.

4 W. Ben, X. Pan and Z. Qiang, Environ. Sci.: Processes Impacts, 2013, 15, 870-875.

5 Y. Luo, L. Xu, M. Rysz, Y. Wang, H. Zhang and P. J. J. Alvarez, Environ. Sci. Technol., 2011, 45, 1827-1833.

6 Y. Bai, W. Meng, J. Xu, Y. Zhang and C. Guo, Environ. Sci.: Processes Impacts, 2014, 16, 586-593.

7 H. Fang, H. Wang, L. Cai and Y. Yu, Environ. Sci. Technol., 2015, 49, 1095-1104.

8 M. B. M. Ahmed, A. U. Rajapaksha, J. E. Lim, N. T. Vu, I. S. Kim, H. M. Kang, S. S. Lee and Y. S. Ok, J. Agric. Food Chem., 2015, 63, 398-405.

9 L. Ji, W. Chen, L. Duan and D. Zhu, Environ. Sci. Technol., 2009, 43, 2322-2327.

10 J. Dai, X. Wei, Z. Cao, Z. Zhou, P. Yu, J. Pan, T. Zou, C. Li and Y. Yan, RSC Adv., 2014, 4, 7967-7978.
11 N. A. Oladoja, R. O. A. Adelagun, A. L. Ahmad, E. I. Unuabonah and H. A. Bello, Colloids Surf., B, 2014, 117, 51-59.

12 O. Hanay, B. Yildiz, S. Aslan and H. Hasar, Environ. Sci. Pollut. Res., 2014, 21, 3774-3782.

13 D. Fernandez-Calvino, A. Bermudez-Couso, M. Arias-Estevez, J. C. Novoa-Munoz, M. J. Fernandez-Sanjurjo, E. AlvarezRodriguez and A. Nunez-Delgado, Environ. Sci. Pollut. Res., 2015, 22, 425-433.

14 Y. Chao, W. Zhu, X. Wu, F. Hou, S. Xun, P. Wu, H. Ji, H. Xu and H. Li, Chem. Eng. J., 2014, 243, 60-67.

15 M. Brigante, M. E. Parolo, P. C. Schulz and M. Avena, Powder Technol., 2014, 253, 178-186.

16 Y. Zhuang, F. Yu, J. Ma and J. Chen, RSC Adv., 2015, 5, 2796427969.

17 S. Hashemikia, N. Hemmatineja, E. Ahmadi and M. Montazer, J. Colloid Interface Sci., 2015, 443, 105-114.

18 Y. Li, Z. C. Feng, Y. X. Lian, K. Q. Sun, L. Zhang, G. Q. Jia, Q. H. Yang and C. Li, Microporous Mesoporous Mater., 2005, 84, 41-49.

19 C. Y. Liu, C. F. Chen, J. P. Leu and Y. C. Lin, J. Sol-Gel Sci. Technol., 2007, 43, 47-51.

20 I. Turku, T. Sainio and E. Paatero, Chem. Lett., 2007, 5, 225228.

21 R. A. Figueroa and A. A. Mackay, Environ. Sci. Technol., 2005, 39, 6664-6671.

22 Y. Zhao, F. Tong, X. Gu, C. Gu, X. Wang and Y. Zhang, Sci. Total Environ., 2014, 470, 19-25.

23 H. P. Vu and J. W. Moreau, Chemosphere, 2015, 119, 987-993.

24 T. Mahmood, S. U. Din, A. Naeem, S. Mustafa, M. Waseem and M. Hamayun, Chem. Eng. J., 2012, 192, 90-98.

25 L. Xiang, S. Royer, H. Zhang, J. M. Tatibouet, J. Barrault and S. Valange, J. Hazard. Mater., 2009, 172, 1175-1184.

26 C. Nozaki, C. G. Lugmair, A. T. Bell and T. D. Tilley, J. Am. Chem. Soc., 2002, 124, 13194-13203.

27 S. Cazalbou, G. Bertrand and C. Drouet, J. Phys. Chem. B, 2015, 119, 3014-3024.

28 X. Liang, R. Yang, G. Li and C. Hu, Microporous Mesoporous Mater., 2013, 182, 62-72.

29 X. Zhu, Y. Liu, F. Qian, C. Zhou, S. Zhang and J. Chen, Bioresour. Technol., 2014, 154, 209-214.

30 M. Jia, F. Wang, Y. Bian, X. Jin, Y. Song, F. O. Kengara, R. Xu and X. Jiang, Bioresour. Technol., 2013, 136, 87-93.

31 R. S. Prakasham, G. S. Devi, K. R. Laxmi and C. S. Rao, J. Phys. Chem. C, 2007, 111, 3842-3847.

32 Y. Wu, Y. Zhang, J. Cheng, Z. Li, H. Wang, Q. Sun, B. Han and Y. Kong, Microporous Mesoporous Mater., 2012, 162, 51-59. 